FRI0370

CLINICAL FEATURES AND OUTCOMES OF LUPUS NEPHRITIS WITH PODOCYTE INJURY IN PATIENTS WITH SYSTEMIC LUPUS ERYTHEMATOSUS

K. Suzuki, Y. Kaneko, R. Anan, H. Takei, T. Takeuchi. Division of Rheumatology Department of Internal Medicine, Keio University School of Medicine, Tokyo, Japan

Background: Lupus podocytopathy is a recently recognised, new class of lupus nephritis (LN) characterised by diffuse foot process effacement (FPE) without capillary wall immune deposits and glomerular proliferation. However, the frequency, clinical features and treatment response to glucocorticoid and additional immunosuppressive agents of podocyte injury has not been well investigated. Objectives: To clarify clinical characteristics of podocyte injury and its association with therapeutic response in patients with $\mathrm{LN}$.

Methods: Consecutive patients with LN with available electronic microscopic findings in our institute were included. Patients were divided into 2 groups according to the presence or absence of FPE (FPE positive group and FPE negative group), and patient characteristics and laboratory data and pathological classification were compared.

Results: Twenty-seven patients with $\mathrm{LN}$ with electronic microscopic findings were enrolled. The mean age was 43.7 years old, and 22 (81.5\%) were female. The ISN/RPS classification of lupus nephritis were 2 of unclassified, 1 class II, 3 class III, 3 class IV, 9 class V, 6 class III+V, and 3 class IV+V. Two cases were identified as lupus podocytopathy and their renal tissues showed focal segmental glomerulosclerosis pattern. Eighteen patients (67\%) were identified to have FPE (FPE positive group) and the remaining 9 patients $(33 \%)$ did not show FPE in their renal tissues (FPE negative group). The mean age was comparable (42.1 vs 41.2 $y / o, p=0.84$ ). The mean estimated glomerular filtration rate (eGFR) at $L N$ diagnosis was 77.5 and $70.9 \mathrm{ml} / \mathrm{min} / 1.73 \mathrm{~m}^{2}(\mathrm{p}=0.39)$, and the mean urine protein was 1.35 and $2.41 \mathrm{~g} /$ day $(\mathrm{p}=0.11)$. During the mean observation period of 50.1 months, 19 patients $(70 \%)$ achieved complete response (CR, urinary protein/urine creatinine ratio $<0.5 \mathrm{mg} / \mathrm{gcr}$ or proteinuria by dipstick test $< \pm$ ). While the dose of prednisolone at treatment initiation and subsequent immunosuppressive therapy was similar in both groups (prednisolone dose, 34.8 vs $39.2 \mathrm{mg} / \mathrm{day}, \mathrm{p}=0.57$ ), the rate of $\mathrm{CR}$ achievement was significantly higher in the FPE positive group (15 cases, $83 \%$ ) than the FPE negative group (four cases, $44 \%, p=0.04$ ). The duration to $\mathrm{CR}$ achievement was also significantly shorter in the FPE positive group (median, 8 vs 2 months, $\mathrm{p}=0.05$ ).

Conclusions: This study showed that podocyte damage was common in LN and pathological types and FPE was associated with renal prognosis in LN. We should be more aware of findings of electronic microscopic in patients with LN.

Disclosure of Interest: None declared

DOI: 10.1136/annrheumdis-2018-eular.5266

\section{FRI0371 CLINICAL CHARACTERISTICS AND OUTCOME OF ISOLATED LUPUS NEPHRITIS}

K. Bugdayli ${ }^{1}$, V.R. Chowdhary ${ }^{1}$, C.S. Crowson ${ }^{1,2}$, L. Zand ${ }^{3}$, M.P. Alexander ${ }^{4}$, L. D. Cornell ${ }^{5} .{ }^{1}$ Rheumatology; ${ }^{2}$ Health Sciences Research; ${ }^{3}$ Nephrology and Hypertension; ${ }^{4}$ Anatomic Pathology, ${ }^{5}$ Anatomic Pathology, Mayo Clinic, Rochester, USA

Background: Lupus nephritis $(\mathrm{LN})$ is a serious manifestation of systemic lupus erythematosus (SLE) associated with significant mortality and morbidity. At least $50 \%$ of patients will develop renal involvement at some point in their disease course. Rarely, patients may present with $\mathrm{LN}$ alone and have no extra-renal clinical manifestations of lupus. The clinical course, response to treatment and subsequent development of extra-renal manifestations of lupus is not well known in this subset.

Objectives: To study the treatment response and development of extra-renal manifestations of lupus in patients who present with isolated lupus nephritis.

Methods: Subjects were identified by searching a pathologic renal biopsy database for patients with immune complex glomerulonephritis and lupus nephritis $(n=1015)$. Clinical records were reviewed for exclusion of infectious and secondary causes (e.g. IgA nephropathy, C1q nephropathy, C3 glomerulonephropathy, post-infectious glomerulonephritis etc.). Cases with isolated LN were defined per 2012 SLICC criteria as having biopsy proven LN with positive antinuclear antibody (ANA) and/or anti-dsDNA antibodies and who did not have any extra-renal clinical manifestations at onset. Demographics, biopsy information, clinical and laboratory features at onset, and during follow-up and treatment was recorded on a standardised data collection form. Complete and partial renal response were defined per the Dutch Working Party criteria. ${ }^{1}$

Results: Thirty four patients with isolated LN were identified. The median age at presentation was 41 years and majority were female $(71 \%)$ Caucasians $(77 \%)$. Median follow up was 5.4 years. At presentation, mean serum creatinine was $1.7 \mathrm{mg} / \mathrm{dl}$ (range $0.7-5.4$ ), and mean proteinuria was $6.8 \mathrm{~g} / 24$ hours (range $0.1-$ 62.9 ). Antinuclear antibodies were positive in $71 \%$, positive dsDNA in $36 \%$. Mean C3 and C4 levels were $78.2 \mathrm{mg} / \mathrm{dl}$ (range 26.5-133.0) and $11.0 \mathrm{mg} / \mathrm{dl}$ (range 3.040.0), respectively. Antibodies to extractable nuclear antigens were checked in 12 patients and positive for anti-SSA, ${ }^{5}$ anti-SSB, ${ }^{2}$ anti-Sm, ${ }^{2}$ anti-RNP $;{ }^{3}$ Anticardiolipin were positive in $7 / 13$ and lupus anticoagulant in $4 / 4$. Renal biopsies showed changes of Class III nephritis in 10 patients (29\%), Class IV in $13(38 \%)$ and class $\checkmark$ in $7(21 \%)$. Induction treatment included Corticosteroids (94\%), mycophenolate mofetil $(76 \%)$, cyclophosphamide $(18 \%)$ and tacrolimus $(3 \%)$. Maintenance treatment included corticosteroids $(73 \%), \operatorname{MMF}(79 \%)$, azathioprine $(8 \%)$, rituximab $(5 \%)$, cyclophosphamide $(5 \%)$, calcineurin inhibitor $(2 \%)$, chlorambucil $(2 \%)$. At the last follow up CR was seen in $14(42 \%)$ and partial response in $5(15 \%)$. Endstage renal disease developed in $6(18 \%)$ and 3 patients received renal transplant. Extra-renal manifestations of lupus developed in 8 patients (24\%) and included acute cutaneous, ${ }^{2}$ chronic cutaneous, ${ }^{3}$ arthritis ${ }^{1}$ and serositis. ${ }^{4}$

Conclusions: Majority of patients with isolated lupus nephritis respond well to treatment. The development of extra-renal manifestations of lupus after treatment is a rare occurrence.

\section{REFERENCE:}

[1] Neth J Med. 2012 May;70(4):199-207.

Disclosure of Interest: None declared

DOI: 10.1136/annrheumdis-2018-eular.6053

\section{FRI0372 COMPARISON OF CLINICAL FEATURES BETWEEN YOUNG AND ELDERLY ONSET IN PATIENTS WITH PRIMARY SJOGREN'S SYNDROME}

M. Kojima ${ }^{1}$, Y. Kaneko ${ }^{1}$, M. Tsukamoto ${ }^{2}$, T. Takeuchi ${ }^{1} .{ }^{1}$ Division of Rheumatology, Department of Internal Medicine, Keio University School of Medicine; ${ }^{2}$ Division of Rheumatology, Department of Internal Medicine, National Hospital Organization, Tokyo, Japan

Background: Primary Sjogren's syndrome (pSS) generally develops in middleaged women. Currently, elderly-onset pSS has been increasing, however, differences in clinical and serological features between young-onset and elderly-onset pSS is unclear.

Objectives: The aim of this study was to compare clinical and serological features between young-onset and elderly-onset patients with pSS.

Methods: All patients with pSS diagnosed with 2016 ACR/EULAR classification criteria in our department from 1995 to 2017 were included. Patients were divided into 2 groups according to the age of diagnosis at 65 years old; young-onset and elderly-onset. The symptoms and laboratory findings were compared.

Results: Six hundred twelve pSS patients were reviewed. Five hundred seventy $(93 \%)$ were female. Four hundred twenty six $(70 \%)$ were young-onset and the remaining $186(30 \%)$ were elderly-onset. The mean age at pSS diagnosis was 47.8 and 72.4 years old, the ratio of women:men is around 12:1 and 20:1. The observation period from the diagnosis to the last visit was 3.46 and 5.50 years, respectively. At diagnosis, the positivity of anti-SS-A antibody ( 86.8 vs $73.7 \%$, $\mathrm{p}<0.001$ ), anti-SS-B antibody ( 48.3 vs $30.7 \%, \mathrm{p}<0.001$ ), and rheumatoid factor ( 49.6 vs $35.2 \%, p<0.01$ ) were significantly higher in the young-onset patients than the elderly-onset patients. Also, the level of platelet cell count $\left(23.0 \mathrm{vs} 20.8^{*} 10^{4} / \mu\right.$ I, p<0.001), IgG (1996 vs $1745 \mathrm{mg} / \mathrm{dl}, \mathrm{p}<0.001)$ and IgM (154 vs $131 \mathrm{mg} / \mathrm{dl}$ $p<0.001)$ were significantly higher in the young-onset patients. On the other hand, that of white blood cell count (4814 vs 5301/ul, $p<0.001)$, neutrophil count (2822 vs $3201 / \mu l, p<0.001)$, lymphocyte count (1512 vs $1632 / \mu l, p<0.01)$, C3 (87.2 vs $93.2 \mathrm{mg} / \mathrm{dl}, \mathrm{p}<0.001), \mathrm{C} 4$ (22.1 vs $24.7 \mathrm{mg} / \mathrm{dl}, \mathrm{p}<0.001$ ), and $\mathrm{CH} 50$ (48.2 vs $51.1 /$ $\mathrm{ml}, \mathrm{p}<0.001$ ) were significantly lower in the young-onset patients. While the young-onset patients had higher rate of liver dysfunction (3.99 vs $0.54 \%, p<0.05$ ), and arthritis $(6.81$ vs $2.69 \%, p<0.05)$, the elderly-onset patients were more frequently complicated with pulmonary disease $(4.2 \mathrm{vs} 11.8 \%, \mathrm{p}<0.001)$. The C 3 levels in the elderly-onset patients with pulmonary disease were conversely lower than the young-onset patients with pulmonary disease. The incidence of lymphoma was not different between two groups.

Conclusions: Although elderly onset pSS patients have milder symptoms and immune-disturbances than young-onset ones, pulmonary disease was more frequently affected in the elderly-onset patients with a decrease in complement levels, suggesting there may be difference in the pathogensis in pSS according to onset ages and organ involvement.

\section{REFERENCES:}

[1] Sjögren syndrome. CMAJ 2014;186(15):E579-586.

[2] Clinical and immunological characteristics of elderly onset Sjögren's syndrome: a comparison with younger onset disease. J Rheumatol 2001;28 (4):795-7.

Disclosure of Interest: None declared DOI: 10.1136/annrheumdis-2018-eular.4344 